\title{
Preface: Geology and information technology
}

\author{
Mauro De Donatis • Chiara D'Ambrogi
}

Received: 27 October 2008 / Revised: 2 March 2009

Accepted: 4 March 2009/Published online: 13 March 2009

(C) Springer Science + Business Media, LLC 2009

The image of geologist is often associated with a "tough natural scientist" operating in the field without technology. This has changed with the large diffusion of information and communication technology; today, geologists face the digital world.

The geological maps and cross sections have been fundamental for synthesizing the geological knowledge of a region, but GIS, 3D digital modelers, and web-based applications allow to easily analyze, interpolate, showing and sharing data, information, interpretations, and thoughts. This new way of operating has deeply affected the new generations of earth scientists and it changed the approach to the knowledge management in geology.

In 2005, the need for communication among people working with digital tools in the earth sciences in Italy lead to the constitution of an informal group called GIT (Geology and Information Technology - www.gitonline.eu) which became later a section of the Italian Geological Society. This special issue showcases some of the main contributions to the second meeting hold in Bevagna (Perugia-, Italy) on 4-6 June 2007.

\section{Papers}

Comparison of GIS-based methodologies for the landslide susceptibility assessment (MAGLIULO et al) The authors test two simple GIS-based methodologies to assess the landslide susceptibility in a basin located in Southern Italy. The methodologies, based on

\footnotetext{
M. De Donatis $(\bowtie)$

Università degli Studi di Urbino "Carlo Bo", Dipartimento di Scienze Geologiche, Technologie Chimiche e Ambientali, Campus Scientifico,

61029 Urbino, Italy

e-mail: mauro.dedonatis@uniurb.it

C. D’Ambrogi

ISPRA - Istituto superiore per la protezione e la ricerca ambientale, Servizio Geologico d'Italia, Via Curtatone, 300185 Roma, Italy

e-mail: chiara.dambrogi@apat.it
} 
the spatial distribution of landslides and/or of causal factors, are bivariate-statistics-based and expert-based, respectively.

GIS-based method for the environmental vulnerability assessment to volcanic ashfall at Etna Volcano (RAPICETTA \& ZANON) The results of a preliminary estimation of vulnerability, attained by the integration of realistic eruptive scenarios with a GIS-based method are presented. The response of environment to ashfall was evaluated aiming at defining the vulnerability in the areas surrounding Mt. Etna volcano, Sicily.

A Preliminary method for the evaluation of the landslides volume at a regional scale (MARCHESINI et al) This paper describes the implementation of an algorithm aimed to define, with an adequate approximation, the 3D geometry of the sliding surface of rotational slides for which, on the basis of geologic maps available at regional scale, some geotechnical parameters can be known or estimated. The work includes the creation of a computer code useful for the 3D analysis of slope stability (3D safety factor) using the simplified Janbu method.

Automated tools within workflows for $3 D$ structural construction from surface and subsurface data (FERNANDEZ et al) Three automated techniques optimize the use of sparse geological and/or geophysical data and enhance the time-efficiency of 3D model construction. The three new automated tools (3D geological contact analysis, 3D dipdomain construction, and 3D isopach measurement and construction) are inscribed in a general workflow for 3D construction.

A WebGIS for the Dissemination of Information on Historical Landslides and Floods in Umbria, Italy (SALVATI et al) In this paper, the authors describe the available information on historical landslides and floods in Umbria region, they perform a temporal and a spatial analysis of the collected historical information. A specific Web site designed to disseminate the available historical information, and WebGIS technology adopted to show the location of the sites historically affected by landslides and inundations are presented.

Comparison of 2-D and 3-D computer models for the M. Salta rock fall, Vajont Valley, Northern Italy (TAGLIAVINI et al) The Authors compare two software designed to model and simulate rock falls: STONE (3D simulation) and RocFall (2D simulation). The two computer programs require similar input and provide comparable outputs, allowing for a quantitative evaluation of their modelling results. The test area is located in Northern Italy.

Application of a model to the evaluation of flood damage (LUINO et al) This paper presents the initial results of a common methodology for the evaluation of damage produced by a flood. A model simulates flood scenarios and evaluates expected economic losses from the impact of floodwaters on exposed elements, has been developed through the application of a computational model elaborated by GIS. It could be used by land administration bodies and insurance companies to manage flood-related damage data. 


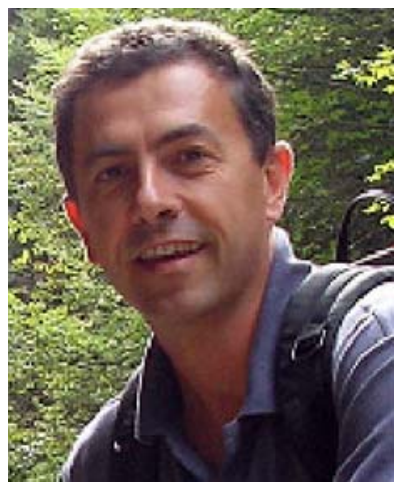

Mauro De Donatis is associate professor at University of Urbino where he received a Degree in Geological Sciences in 1987. He also received a post-graduate qualification in Geological Cartography in Bologna (1988) and a M.Sc. degree in Basin Evolution and Dynamics from Royal Holloway (University of London, 1996). He has been consultant for regional and national geological cartography projects and oil companies. His current research is mainly focused on methodology for advanced geological mapping with mobile-GIS and 3D models. He is a national coordinator of GIT-Geology and Information Technology Group.

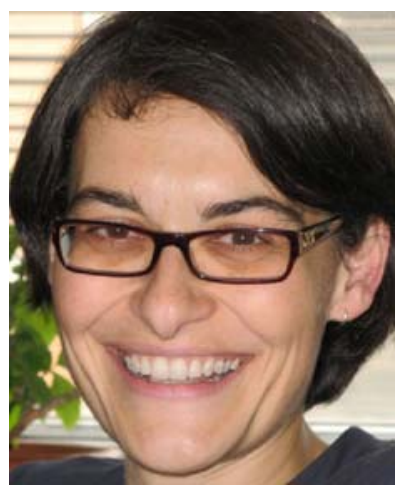

Chiara D'Ambrogi Chiara D'Ambrogi received both her Degree in Geological Sciences (1995) and her PhD in Earth Sciences (1999) from the University of Rome "La Sapienza". Since 1999 she works as geologist in Geological Survey of Italy (SGI). Her activities are focused on field survey of central-northern Apennines, Neogene stratigraphy, geological mapping and 3D geological modeling. She is coordinator of Northern Apennines Committee for national geological mapping project (1:50,000 scale); from the 2006 she is coordinator for the activities of SGI concerning the 3D geological modeling. 